\title{
Correction to: Asthma Control and Its Predictive Factors in Adult Asthma Patients
}

\author{
Eman Albataineh ${ }^{\mathrm{a}, \mathrm{g}}$, Enas Al-Zayadneh ${ }^{\mathrm{b}}$, Hani Al-Shagahin ${ }^{\mathrm{c}}$, Ahlam AL Soloman ${ }^{\mathrm{d}}$, \\ Areej Altarawnehe ${ }^{\mathrm{e}}$ Ibrahim Aldmour ${ }^{\mathrm{f}}$
}

This is to correct the published article, Journal of Clinical Medicine Research, 2019;11(12):807-817. doi: 10.14740/jocmr4021.

The authors would like to change the affiliation of the second author, Enas Al-Zayadneh ${ }^{\mathrm{b}}$, it should read as fol- lows:

${ }^{b}$ Department of Pediatrics, School of Medicine, University of Jordan, Jordan.

Previous address: Department of Pediatrics, College of medicine, University of Mutah, Jordan.

'Department of Special Surgery, Faculty of Medicine, Mutah University, AlKarak, Jordan

dPrince Ali Bin Al Hussein Hospital, Al-Karak, Jordan

eAlbasheer Hospital, Amman, Jordan

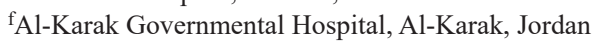

'Corresponding Author: Eman Albataineh, Department of Microbiology and Immunology, Faculty of Medicine, Mutah University, Al-Karak, Jordan.

Email: emanbatayneh@yahoo.com

doi: https://doi.org/10.14740/jocmr4021c1 